\title{
Anomalies of Mullerian ducts
}

Padhye SM

Saraswati M Padhye, Professor, Department of Obstetrics and Gynaecology, Kathmandu Medical College Teaching Hospital, Kathmandu, Nepal

\section{Abstract}

Some form of mullerian anomalies occur in one out of 4000 to 5000 females. A girl presenting with primary amenorrhoea, pelvic pain and sub fertility is likely to have some or other form of mullerian anomalies. Here, we present seven cases of mullerian anomalies who were treated at Kathmandu Medical college Teaching hospital in seven years. Absence of vagina usually is not obvious in a female baby at the time of birth. It is only when the secondary sex characters develop; time of menarche is awaited but one does not menstruate that the parents start wondering why her menstruation did not start.

Key words: Mullerian malformation, primary amenorrhoea, vaginal agenesis

\section{INTRODUCTION}

M enstrual disturbances are supposed to be worrying to a woman especially in developing countries. When a girl reaches adolescence, the parents expect her to have normal period and start thinking about "marriage."

Amenorrhoea is defined as absence of having period (1) by the age of 13 years who lacks other evidence of pubertal development; (2) by age 15, even in presence of other pubertal signs; or (3) for a length of time equivalent to a total of three previous cycle intervals or 6 months'. Amenorrhoea has classically been classified as primary (no prior menses) or secondary (cessation of menses) ${ }^{1}$. Primary amenorrhoea could be due to the embryological defects such as mullerian anomalies- agenesis or dysgenesis. Agenesis results from one or the other defect of the mullerian ducts leading to abnormalities of genital tract and this is a complex phenomenon.

Mullerian anomalies are classified as, segmental mullerian hypoplasia or agenesis, may be vaginal, cervical, uterine, tubal or combined' 1 .

The objective of this article is to share the experiences. Here, seven cases of primary amenorrhoea admitted

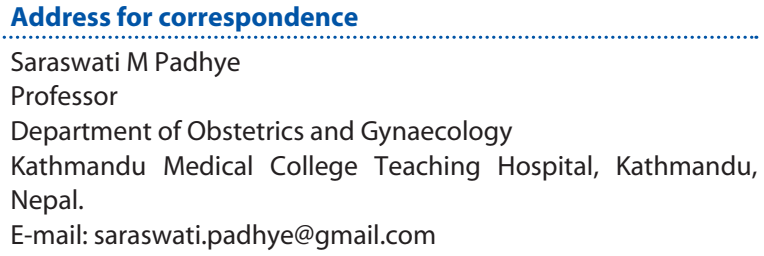

from June 2006 to 2013 (BS. 2063 to 2070) at Kathmandu Medical College Teaching Hospital, Kathmandu, Nepal are presented.

\section{CASE REPORTS}

\section{CASE 1}

A girl aged 13 years presented with severe cyclical pain abdomen for last few months and noticed a swelling in the abdomen. She had not started menstruation. She was admitted on 2006 June 21 (BS 7/3/2063).

On examination, she had good health, secondary sex characters were developed. Systemic examination was normal. On abdominal examination there was a centrally situated, cystic mass equivalent to 16 weeks size uterus. Local examination revealed absence of normal vagina but a small dimple was present. On rectal examination the pelvis was full with a soft mass.

Ultrasonography (USG) revealed that uterus was enlarged $114 \times 57 \times 54 \mathrm{~mm}$ with mixed echogenic fluid in the endometrial cavity and cervical canal. External cervical os was stenosed: a case suggestive of haematometra-haematocolpos (Figure 1).

Examination under anaesthesia was performed and the findings were confirmed. Laparotomy and a vertical hysterotomy was decided. Drainage of haematometra and haematocolpos was done through a vertical hysterotomy. A number 7 Foley catheter was introduced through the hypoplastic cervix and fixed in the uterine cavity to drain the remaining old blood. The hypoplastic 
cervix was located after dissecting the vertical septum of the vagina from below and a neo vagina was made. Two fingers could be introduced in the neovagina.

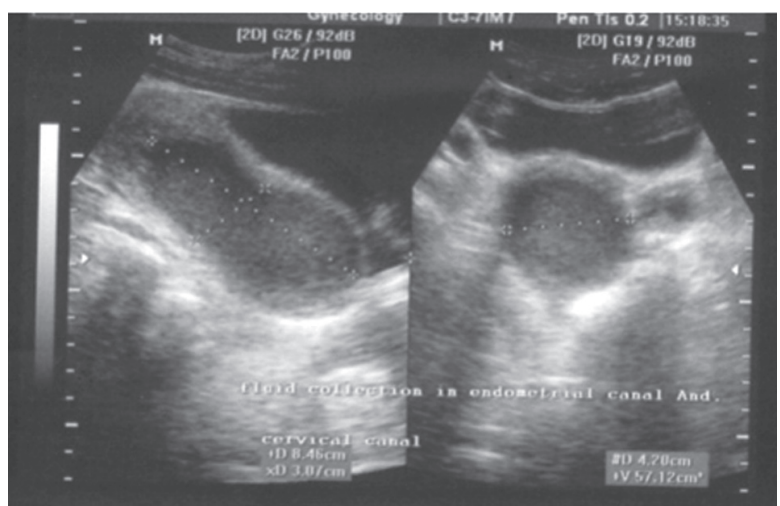

Figure 1: Enlarged uterus with haematometra and haematocolpos (case 1).

A mould was prepared with introduction of gauge inside a latex condom. Fresh human amnion was wrapped over the mould. Vagina was about four $\mathrm{cm}$. Thus prepared mould was inserted in the neovagina and fixed with non-absorbable sutures. A number 12 Foley catheter was inserted in the bladder. Her post-operative period was uneventful. The old blood was slowly draining through the number 7 catheter which was renewed after one week and removed when there was no more blood draining. The mould came out on the fifth day. External sutures were removed.

She was discharged with advice to keep on dilating the vaginal orifice. She returned back three months later with same complaints. The vaginal orifice was about $2 \mathrm{~mm}$ with scarred tissue. Vaginal dilatation and aspiration of old blood after dissecting the scarred tissue under general anaesthesia was done. She had repeated dilatation of vagina under general anaesthesia. She was well and discharged with same advice.

She returned back after 16 months with retention of the urine which was drained and measured three litres.

She again underwent vaginoplasty after two years of first operation with skin graft from her right thigh. She was taken to the theatre after four weeks and repeated vaginal dilatation was done. Again she was discharged from the hospital.

She came back after three months with severe pain and absence of regular menses. USG done during readmission showed uterine size to be $130 \times 54 \times 45 \mathrm{~mm}$ with haematometra-colpos.
At the span of three years she was admitted repeatedly for seven times and treated but there was no success. She was discharged on request as she wanted to go outside this country.

\section{CASE 2}

A 15 year girl was admitted on 2008 July 7 (BS 23/3/2065) with history of severe cyclical pain for last two years. She had undergone surgical treatments twice at different hospitals twenty months and two months back. Her general condition was fair, secondary sex characters were fully developed. Systemic examination revealed no abnormalities. Local examination showed scarred tissue at vaginal orifice.

USG showed normal outline and endotexture of the uterus. Fluid collection of $232 \mathrm{ml}$ in the vagina haematometra, haematocolpos with haematosalpinx was noted. Cervix was visualized. Left kidney was relatively smaller than the right one (Figure 2). Per rectum a mass was detected in the pelvis.

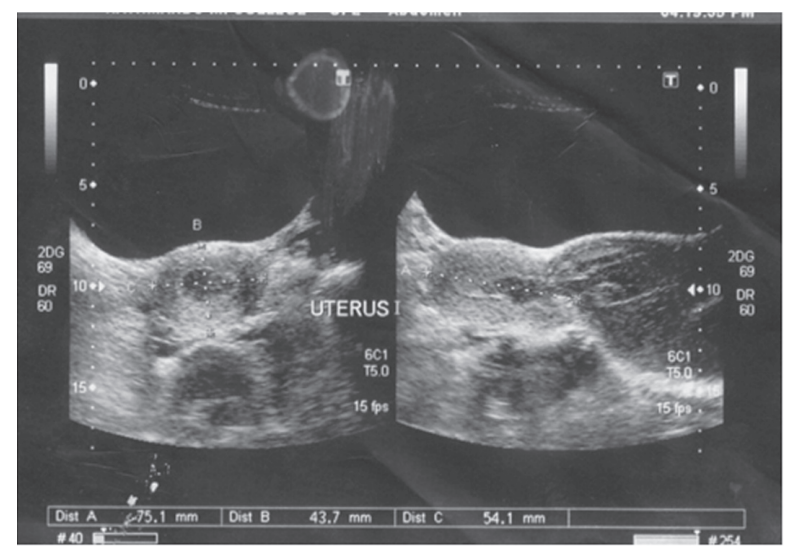

Figure 2: USG showing haematometra, haematocolpos with haematosalpinx (case 2).

Drainage of $200 \mathrm{ml}$ of old blood was carried out and vaginoplasty was done using human fresh amnion as in case number 1. Number 24 silicon Foley catheter was inserted in the vagina and she was sent home after removal of stitches with instructions to change the bag and to maintain general hygiene of the area.

She came back after four months with very heavy menses that required blood transfusion. Diagnostic laparoscopy was done. The uterus was small; there was bilateral hydrosalpinx and polycystic ovaries. Foley catheter was removed as the vagina was found about 4-5 cm deep. Subsequently, she failed to come for follow up. 


\section{CASE 3}

A woman aged 22 years was admitted on 2010 January 31 (BS 17/10/2066) for primary amenorrhoea. She had undergone diagnostic laparoscopy seven years back in this institution. She was diagnosed as a case of small bicornuate uterus. She came for the treatment of primary amenorrhea and subfertility. She was having regular intercourse with some difficulty. Her general condition was good, her secondary sex character was normally developed. Systemic examination was within normal limit. On local examination there was a dimple at the site of vagina though the skin was loose. Bimanual and rectal examination revealed almost same findings as mentioned in the previous note. No definite cervix was palpable.

Vaginoplasty was decided. There was small injury to the anterior rectal wall during the dissection of urethrorectal space. It was repaired in layers. Meanwhile mini laparotomy also was done and tried to fix the uterus and a vertical hysterotomy was done and a cervical dilator was pushed down to see the site of the cervix but it was possible to trace neither the cervix nor the vault of vagina. A mould was fixed as in case number 1 . Postoperative period was uneventful.

After one week she wanted to go home due to domestic problems and discharged on request with advice to come after three months. She was explained about the need of repair of the fistula after three months.

She came back after nine months. The vagina looked shallow, faecal matter was seen at vagina. There was 0.5 $\mathrm{cm}$ hole at vagina, a recto vaginal fistula was diagnosed which was repaired with standard technique. Her vagina was about $5 \mathrm{~cm}$ deep. There was no leakage of faecal material. She was counselled about her reproductive outcome and sent home.

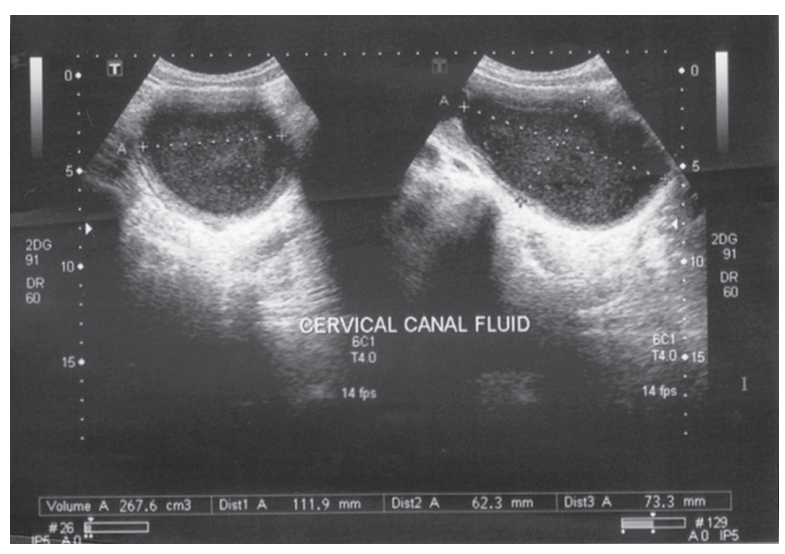

Figure 3: USG showing fluid in the cervical canal (case 4).

\section{CASE 4}

A girl aged 15 years was seen in emergency room on 2009 November 12 (BS 26/7/2066) with complain of severe pain abdomen and a cystic mass measuring $7 \times 6$ $\mathrm{cm}$ which turned out to be a haemorrhagic cyst on USG (Figure 3).

She gave history of having treatment somewhere else and had some operation six months back for same kind of problems. On examination her general condition was good. Her systemic examinations were within normal limits. Per abdomen there was a mass equivalent to 20 weeks size of uterus. Local examination revealed a scar at the fourchette.

There was haematometra, fluid collection at cervical canal but the cervix was stenosed, a vaginal septum was noted which was dissected, a large-bore needle was introduced high up and drainage of $700 \mathrm{ml}$ of old blood was performed. Vaginoplasty was done using fresh human amnion after incising the vaginal septum and exposing the small cervix. Old blood was draining slowly. USG showed normal sized uterus after three weeks.

She was discharged after instructing to keep on dilating. She failed to come back for follow up.

\section{CASE 5}

An adult woman aged 30 years was brought by her cousin requesting 'Hysterectomy' for very severe pain every month. She had to be taken to the hospital to give parenteral analgesics to relieve pain. She was advised to have hysterectomy somewhere while undergoing the treatment.

She had suffered for last 15 years. She was well till the age of 13 years after which she had severe pain every now and then almost every month and had to be taken to the hospital. She was taken to India (Sitamarrhi) and probably the blood was evacuated at the age of 14 years. Within two year span she was again operated at Patna (India) and stayed in the hospital for one week. The operation did not help her. She had no documents of the previous treatments.

She gave history of development of breast at the age of 11 years and it was fully developed by 14 years.

She was admitted to the hospital on 2010 August 9 (BS 24/4/2067).

She was of average built. Her general condition was fair. She had well developed secondary sex characters. 
She had mild anaemia and vitals were within normal limits. Her heart and lungs were normal. On abdominal examination there was a mass equivalent to 14 weeks size uterus- shifted to the left side, not mobile, margins were not clear. On local examination, the mons, labia majora, labia minora, urethral orifice looked normal. There was absence of vaginal orifice but a scarred tissue was present. Through the scarred shallow vagina and per rectum, a firm mass about $10 \times 10 \mathrm{~cm}$ was felt anterior to the rectal wall about $3-4 \mathrm{~cm}$ high up which was not mobile.

USG revealed right adnexal cyst suggestive of chocolate cyst $(11.6 \times 9.9 \times 7.4) \mathrm{cm}$, cystic mass in the cervix, likely encysted haematoma of $(4.0 \times 4.8 \times 3.1) \mathrm{cm}$, gross right hydronephrosis and moderate left hydronephrosis.

Examination under anaesthesia confirmed previous findings. As she was having severe pain, about $300 \mathrm{ml}$ of old black blood (probably collected menstrual old blood) was aspirated with Tohey needle under guidance of ultrasonography.

USG done after aspiration revealed that the chocolate cyst was $9.3 \times 7.5 \times 7.2 \mathrm{~cm}$, small amount of intra-uterine fluid, hydronephrosis in the right kidney and minimal in the left one.

After recovery from anaesthesia, her pain had subsided. Her cousin was counselled about laparotomy.

After one week the patient and her cousin requested to get the uterus removed for relieving this type of pain forever which she had been having for last 17 years. Pros and cons of hysterectomy were explained. They insisted for hysterectomy as they were fed-up of going to hospitals for pain very frequently which was expensive, time consuming and difficult for them.

Laparotomy was done. The pelvis was full of adhesions. Adhesions were dissected taking help of a surgeon. As there was large mass about $10 \times 6 \mathrm{~cm}$ attached to the bladder and uterus on the right side, the operation was difficult. The finding was unicornuate uterus with endometriotic cyst and haematosalpinx on the right side. Right sided unicornuate uterus along with upper two third of vagina was removed after careful dissection. Some ovarian tissue (which was thought anatomically) on the right was conserved. There was also a small noncommunicating rudimentary horn of the uterus on the left side about $3 \times 2 \times 1 \mathrm{~cm}$ with long Fallopian tube and polycystic ovary (Figure 4,5 ). The left tube and rudimentary horn of the uterus of left side were removed and polycystic ovary was dealt with by drilling the cysts. Kidneys were of normal size.

Haemostasis was maintained and abdomen was closed in layers. Her post-operative period was smooth, she was happy to know that she would not have cyclical pain in the future. She was discharged from the hospital in good condition.

Histopathology Report: "Rudimentary horn of the uterus: proliferative endometrium. Cervix and tube: unremarkable. Proliferative endometrium surrounded by unremarkable myometrium. Cystic brown tissue measured $7 \times 6 \mathrm{~cm}$ : a haemorrhagic cyst."

The patient was well. She got married after two years of operation to a widower with children.

At the span of 15 years the patient had had repeated operation elsewhere (India) without relief. As her concern was to get relief of pain she submitted for hysterectomy which seems to be justified treatment in this case.

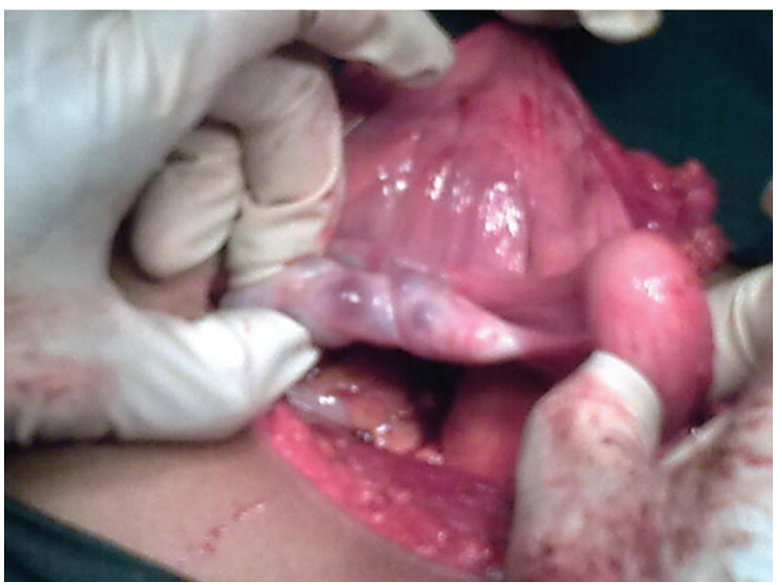

Figure 4: Photograph of left rudimentary horn of uterus and polycystic ovary (case 5).

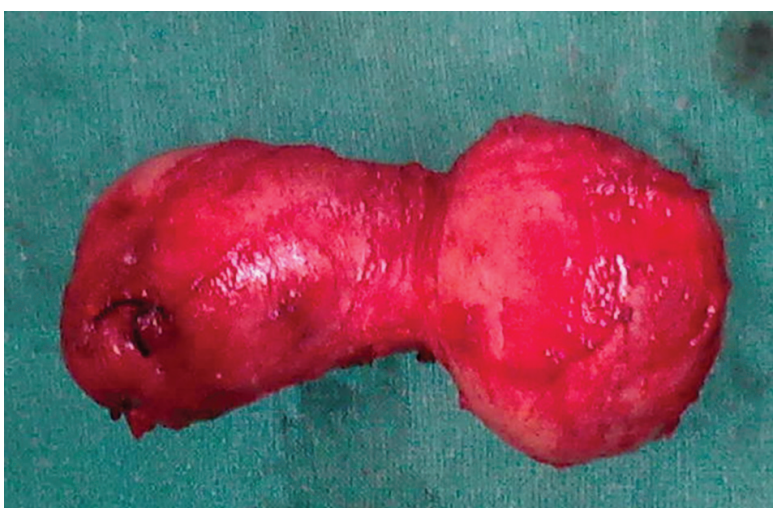

Figure 5: The main uterus of right side and vagina removed in-toto was of "Dumb-bell" shape (case 5). 


\section{CASE 6}

A patient aged 18 years, married for two years, came to the Gynaecology- outdoor with complain of cyclical pain for last four years and pain during intercourse for last two months. She said that she had not yet menstruated.

On examination her general condition was good, her systemic examination were within normal limit. There was no mass per abdomen. On local examination blind vagina of about two $\mathrm{cm}$ was present. She was admitted on 2014 May 12 (BS 29/2/2070).

USG showed uterus measuring $64 \times 33 \times 45 \mathrm{~mm}$ with distended distal vagina and the cervix. Lower cervical canal and vagina were filled with fluid. Magnetic Resonance Imaging (MRI) reported vaginal agenesis with suspected vaginal septum and irregular haemorrhagic cyst in ovaries.

She underwent vaginoplasty. There was very small injury of the anterior wall of the rectum which was repaired in layers. Fresh human amnion was used, her postoperativeperiod was uneventful. She had no leakage of faecal matter per vaginum, and did not subsequently develop any fistula. She was discharged with advice to insert the plastic vaginal mould for six weeks. When she came back after six weeks, the vagina was $4-5 \mathrm{~cm}$ and she was having sexual intercourse with slight difficulty. She wanted to come after a few months for further treatment. She was advised to take contraceptive pills continuously to relieve her cyclical pain.

\section{CASE 7}

A girl aged 14 years was admitted on 2013 December 9 (BS 24/8/2070) with history of severe pain and fainting attacks during periods since her menarche for last two years.

She had undergone laparotomy 20 months back on May 7, 2012 in other hospital and excision of right sided tissues of uterus had been done -which revealed to be endometriosis involving ovary and Fallopian tube in the histological report. Despite the surgery, she had not been relieved of her symptoms.

She was of small built weighing $35 \mathrm{~kg}$. Her general condition was good, with no pallor. Secondary sex characters were well developed. Systemic examinations were normal. Per abdomen there was a scar at right quadrant of abdomen of about $10 \times 2 \mathrm{~cm}$ with a vague mass palpable below the scar.
Her pre-operative haematological tests, X-ray chest and ECG were normal. Ultrasonography revealed two separate uteruses (Figure 6), cervix and vaginal canal with echogenic-collection in right vaginal canal - suggestive of haematocolpos; simple left ovary, non-visualized right kidney which were also confirmed by CT-IVP.

Examination under anaesthesia (EUA) and laparotomy was decided. EUA revealed normal vulva, vagina and a cervix contradictory to the imaging findings. There were no two cervices. Only one cervix which was flush with vagina could be negotiated. A uterine sound was introduced through the cervix which was felt at left horn of the uterus. On the right side there were adhesions, a cystic ovary but no Fallopian tube. On the left side the tube and ovary were normal (Figure7). Right sided kidney was absent.

Hemi-hysterectomy of right side was performed, haemostasis was secured and abdomen was closed in layers. Her post-operative period was uneventful.

She was discharged with advice to come for follow up after the period. She got re-admitted after one month with wound infection but she had no period after the operation. The girl did not show up for further follow-up.

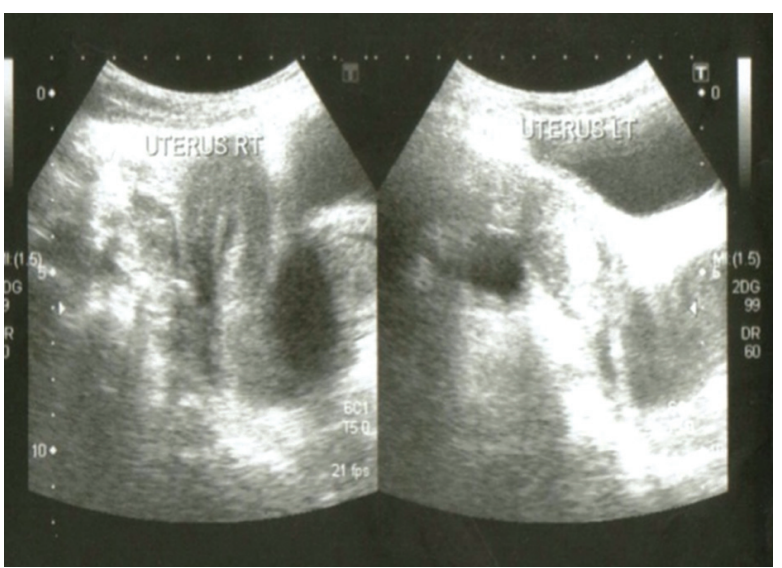

Figure 6: USG showing two separate uteruses (case 7).

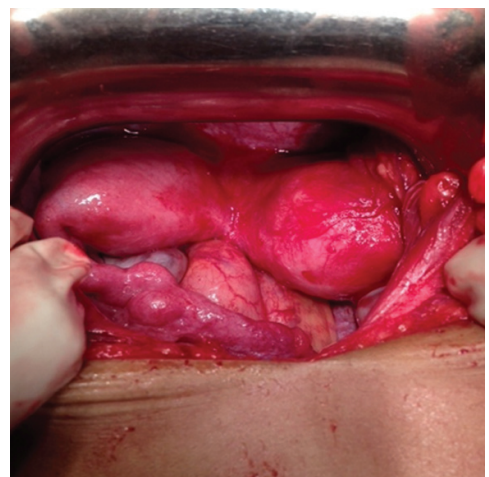

Figure 7: Photograph showing two uteruses (case 7) 


\section{DISCUSSION}

All seven patients of Mullerian dysgenesis came from very poor family and from far off regions of Nepal. Four cases were brought by the parents. Parents start worrying when a female child does not start menstruating even after developing secondary sex characters. Menstruation is taken as a sign of good health when a woman gets periodic, regular well-orchestrated repeating cycle once a month ${ }^{2}$. One case was brought by patient's cousin and the other two cases were by the husbands with history of primary amenorrhea, cyclical pain, mass per abdomen and subfertility. Due to monetary and difficult geographical communication-constrains none of them could afford to spend enough money for the treatment.

All looked healthy, phenotype-females with well developed secondary sex characters. Their systemic examinations were within normal limits. All preoperative investigations were normal. Ultrasonological examinations revealed almost confirmation of clinical findings. There was no clear-cut description of the cervix. So was found during the operating procedures of the cases. It is reported in the literature as: most of the Ulrasonologists usually overlook or miss the findings of vaginal pathology in USG, CT Scan/MRI done for nongynecologic indications due to probe positioning and/or poor vaginal tissue characterization. Knowledge about embryology, development of vagina and understanding of congenital, developmental, and postoperative vaginal disease entities is essential. "Look beyond" the uterus, cervix and vagina has to be kept in the mind of ultrsonogists.

Anatomical abnormalities due to embryological entities, i.e. Mullerian dysgenesis were the causes. Congenital defects of vagina or atresia is estimated to be 1:500010000 live female birth ${ }^{3}$.

The age range of the patients was from 13 to 30 years, mean age being 18. Out of seven cases only two were married of whom one came for the treatment of

\section{REFERENCES}

1. Schorage JO, Schaffer Jl, Halvorson LM, Moffman $\mathrm{BL}$, Bradshaw KD, Cunningham FG, editors. Williams Gynaecology. 1st ed. USA: McGraw Hills companies; 2008. Chapter 18, Anatomic Disorders; p. 402-25.

2. Queenan JT Jr. The Menstrual Cycle. In: Lewis V, editor. Reproductive Endocrinology and Infertility. Landes Bioscience; 2007.

3. Walker DK, Salibian RA, Salibian AD, Belen KM, Palmer SL. Overlooked diseases of the vagina: a directed anatomic-pathologic approach for imaging assessment. Radiographics. 2011 Oct;31(6):1583-98. subfertility, the other five for pain and one for pain as well as subfertility.

Case-related appropriate treatment was planned. One case had repeated admissions and interventions without success and was taken out by a foreigner for the treatment. Second case also came from far off. She was readmitted with the history of menorrhagia needing blood transfusion that means her uterus and vagina was functional. She was keen to study nursing but she did not communicate. The third case came with the report of diagnostic laparoscopy done at the age of 15 years in this hospital. On attempting vaginoplasty there was rectal injury which was repaired nine months later successfully but her fertility function was not encouraging. She was counselled in that line. Fourth case did not turn up after she was discharged from the hospital. The fifth case could be included in the Class IV of American Society for Reproductive Medicine (ASRM) 5 . In spite of vigorous counselling she opted for hysterectomy, because of long suffering it was appropriate to offer the treatment and removal of right rudimentary horn (which is more common) along with the right Fallopian tube with conservation of ovaries to this case was appropriate treatment ${ }^{5}$.

For the sixth case it was planned to do utero-vaginal canalizing procedure. Therefore she had been advised to continue oral contraceptive pills (OCP) till further management and advice ${ }^{6}$. The seventh case had hemihysterectomy of right side. Some authors suggest hemi-hysterectomy in cases where there is thick walled, massive ovarian involvement, endometriosis and adenomyosis. There was no collection on cut section of the specimen after the operation. Histopathology reports and follow up of the case has been awaited ${ }^{7}$.

\section{CONCLUSION}

Anomalies of Mullerian ducts present differently. The management also varies. It is challenging to treat such cases.

4. Saxena AK. Vaginal Atresia [Internet]. 2012 Apr 10. Available from: emedicine.medscape.com/ article/954110-workup

5. Heinonen PK. Uniconuate uterus and rudimentary horn. Fertil Steril. 1997 Aug; 68(2).

6. Fujimotto VY, Miller JH, Klein NA, Soules MR. Congenital cervical atresia: Report of seven cases and review of the literature. Am J Obstet Gynecol. 1997 Dec;1419-25.

7. Rock JA. TeLinde's Operative Gynecology. 10th ed. India: Wolters Kluwer (India) Pvt Ltd. Surgry for Anomalies of the Mullerian Ducts. p. 539-84. 